\begin{tabular}{|c|c|}
\hline Title & Modular synthesis of oligoacetylacetones via site selective sily lation of acetylacetone derivatives \\
\hline Author(s) & Sarkar, Parantap; Inaba, Y uya; Shirakura, Hay ato; Y oneda, Tomoki; Inokuma, Y asuhide \\
\hline Citation & $\begin{array}{l}\text { Organic \& biomolecular chemistry, 18(17), 3297-3302 } \\
\text { https://doi.org/10.1039/d0ob00501k }\end{array}$ \\
\hline Issue Date & $2020-05-07$ \\
\hline Doc URL & http:/hdl.handle.net/2115/81119 \\
\hline Type & article (author version) \\
\hline Additional Information & There are other files related to this item in HUSCAP. Check the above URL. \\
\hline File Information & Revised_manuscript (Org. Biomol. Chem.).pdf \\
\hline
\end{tabular}

Instructions for use 


\section{Modular synthesis of oligoacetylacetones via site-selective silylation of acetylacetone derivatives}

Received 00th January 20xx, Accepted 00th January 20xx DOI: $10.1039 / x 0 x \times 00000 x$

\begin{abstract}
Parantap Sarkar, *a Yuya Inaba, ${ }^{\text {b }}$ Hayato Shirakura, ${ }^{\text {b }}$ Tomoki Yoneda ${ }^{\mathrm{b}}$ and Yasuhide Inokuma*a,b
Oligoacetylacetones consisting of 3,3-disubstituted pentane-2,4-diones were synthesized through the terminal silylation and oxidative coupling protocol. Highly selective formation of mono-enol silyl ethers of 3,3-disubstituted acetylacetones was achieved using 1,8-diazabicyclo[5.4.0]undec-7-ene (DBU) as a base. Subsequent silver(I) oxide mediated coupling reactions provided tetraketones. Unique substituent dependence was found for the terminal-selective silylation of tetraketones. Finally, octaketones (tetramers of acetylacetone derivatives) with three types of monomer sequence were prepared as their discrete forms. Single crystal X-ray analysis revealed that the solid-state conformations of oligoketone chains were predominantly governed by the ketone sequence rather than substituents. However, differences in the packing structures induced by alkyl substituents led to significant difference in melting points for the structural isomers of octaketones.
\end{abstract}

\section{Introduction}

From biological synthesis to industrial use, aliphatic polyketones are widely used as structurally flexible and synthetically versatile components. ${ }^{1-3}$ Their reactivity drastically changes depending on the sequence of carbonyl groups and other substituents on flexible hydrocarbon chains. For example, natural type polyketones with a repeating 1,3-diketone sequence tend to undergo intramolecular cyclization to form six-membered rings. ${ }^{4}$ Polyketones produced by copolymerization of olefin and carbon monoxide have a repeating 1,4-diketone sequence that is capable of Paal-Knorrtype reactions to form pyrrole or furan rings. ${ }^{5}$ We have recently demonstrated stepwise synthesis of discrete, long oligoketones comprising of alternating 1,3- and 1,4-diketones. ${ }^{6}$ The usefulness of these oligoketones have been shown by applications to $\pi$-conjugated chromophores, ${ }^{7}$ ion-conducting materials, ${ }^{8}$ and metal complexes. ${ }^{9}$ The key step in the synthesis of such oligoketones as their discrete forms was site-selective synthesis of enol silyl ethers to be used for elongation of main chains via silver(I) oxide mediated coupling reactions. In the initial attempts, only 3,3-dimethylpentane-2,4-dione (1a) was used as monomer, therefore, the scope and limitations of the approaches are still unknown for other acetylacetone derivatives with different substituents at the 3-position. Moreover, derivatization of discrete oligoketones is also important for the modulation of preferable conformations and reactivities as well as properties of their derivatives. Here, we

\footnotetext{
a. Institute for Chemical Reaction Design and Discovery (WPI-ICReDD), Hokkaido University, Kita 21, Nishi 10, Kita-ku, Sapporo, Hokkaido 001-0021, Japan.

b. Division of Applied Chemistry, Faculty of Engineering, Hokkaido University, Kita 13, Nishi 8, Kita-ku, Sapporo, Hokkaido 060-8628, Japan

†Electronic Supplementary Information (ESI) available: [General experimental details, ${ }^{1} \mathrm{H}$ and ${ }^{13} \mathrm{C}$ NMR spectra, and X-ray data]. See DOI: 10.1039/x0xx00000x
}

report modular synthesis of discrete oligoketones via terminalselective silylation reactions. 3,3-Disubstituted acetylacetone analogues 1 were almost exclusively converted to mono-enol silyl ethers 2 using 1,8-diazabicyclo[5.4.0]undec-7-ene (DBU) as the base. Tetraketones obtained by homo- or cross-coupling reactions of $\mathbf{2}$ exhibited substituent-dependence upon terminal silylation. This modular approach enabled to prepare discrete octaketones with different substituents. Single crystal X-ray analysis of octaketones revealed that the figure-S conformations are governed by the sequence of carbonyl groups, but independent of alkyl-substituents. Nonetheless, melting points of regioisomers were significantly different reflecting their small differences in the packing structures.

\section{Results and discussion}

Selective mono-silylation of 3,3-dimethylpentane-2,4-dione (1a) was previously achieved in high yield using chlorotrimethylsilane and $\mathrm{DBU}$ as a base in a refluxing dichloromethane (Table 1 , entry 1$).{ }^{6}$ In this reaction, DBU was essential to effectively suppress the second silylation. When triethylamine, a common base for silylation, was used with Nal, formation of mono- and bis-silylated products $\mathbf{2 a}$ and 2'a were detected in a 35:65 NMR ratio (see ESI, Figure S1). Therefore, these reaction conditions were applied for other 3,3disubstituted acetylacetone analogues $\mathbf{1 b}-\mathbf{d}$ those could be obtained through direct substitution from acetylacetone in high yields. ${ }^{10-12}$ While 1,1-diacetylcyclohexane (1b) was converted to enol silyl ether $\mathbf{2 b}$ in $90 \%$ yield under the similar conditions, reaction with 1,1-diacetylcyclopropane (1c) resulted in formation of a mixture of mono- and bis-silylated products $\mathbf{2 c}$ and 2'c (78:16, NMR ratio), along with $6 \%$ of starting material 1c. Because of hydrolysis on silica gel, $2 \mathrm{c}$ was isolated in $51 \%$ yield. When the reaction was performed at room temperature, 1c was fully converted to give mono-silylated product $\mathbf{2 c}$ in a 
similar yield (78\% NMR yield, 56\% isolated yield), suppressing the formation of bis-silylated product 2'c to $3 \%$. The DBU conditions were also effective for an aromatic analogue, 3,3dibenzylpentane-2,4-dione (1d), and mono-silylated product $\mathbf{2 d}$ was almost exclusively obtained in $95 \%$ yield. Single crystal Xray diffraction analysis of $\mathbf{2 d}$ confirmed the presence of a trimethylsilyl group, while other acetyl group remained unreacted (Figure S4 in ESI).

Table 1 Formation of mono-enol silyl ethers from acetylacetone derivatives.

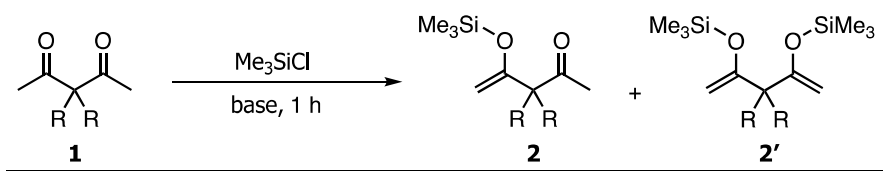

\begin{tabular}{|c|c|c|c|c|c|c|}
\hline Entry & $\mathrm{R}^{\prime} \mathrm{R}$ & 1 & temp. $\left({ }^{\circ} \mathrm{C}\right)$ & base & $2(\%)^{a}$ & $\mathbf{2}^{\prime}(\%)^{b}$ \\
\hline $1^{c}$ & & $1 a$ & 40 & DBU & $2 a(93)$ & 2'a $(<3)$ \\
\hline $2^{d}$ & Me Me & $1 a$ & 40 & $\mathrm{Et}_{3} \mathrm{~N}$ & $2 \mathrm{a}(23)^{b}$ & 2'a (42) \\
\hline $3^{c}$ & & $1 b$ & 40 & DBU & 2b (90) & 2'b (n.d.) \\
\hline $4^{c}$ & & $1 c$ & 40 & DBU & $2 \mathrm{c}\left(78^{b, e}\right)$ & 2'c (16) \\
\hline $5^{c}$ & & $1 c$ & r.t. & DBU & $2 c\left(78^{b, f}\right)$ & $2^{\prime} c(3)$ \\
\hline $6^{c}$ & $\mathrm{Ph}-$ & $1 d$ & 40 & DBU & 2d (95) & $\mathbf{2}^{\prime} \mathrm{d}$ (n.d.) \\
\hline
\end{tabular}

${ }^{a}$ Isolated yield. ${ }^{b} \mathrm{NMR}$ yield. ${ }^{c} \mathrm{Me} 33 \mathrm{SiCl}$ (1.2 eq.), $\mathrm{DBU}$ (1.3 eq.), $\mathrm{CH}_{2} \mathrm{Cl}_{2} .{ }^{d} \mathrm{Me}_{3} \mathrm{SiCl}$ (1.2 eq.), $\mathrm{Et}_{3} \mathrm{~N}$ (1.5 eq.), $\mathrm{Nal}$ (1.2 eq.), $\mathrm{MeCN} .{ }^{e}$ Isolated yield: $51 \% ; 6 \%$ of starting material $1 \mathrm{c}$ remained. ${ }^{f}$ Isolated yield: $56 \%$.

Enol silyl ethers $\mathbf{2 a - d}$ were used as monomers for the synthesis of homo- and hetero-dimers $3 a-f$ by means of silver(I) oxide mediated coupling reaction (Table 2 ). In the previous report, ${ }^{6}$ we have found that yield of dimer $3 a$ increased as the reaction solvent became much polar. Here, the coupling reactions of $\mathbf{2} \mathbf{a}-\mathbf{d}$ were examined in a mixture of dimethyl sulfone and dimethyl sulfoxide at $100{ }^{\circ} \mathrm{C}$ that was the best reaction media for the synthesis of dimer $3 a$.

Cyclohexane analogue $\mathbf{2} \mathbf{b}$ underwent homo-coupling to give dimer $\mathbf{3 b}$ in a comparable yield $(68 \%)$ to $3 \mathbf{a}$. The coupling yield of cyclopropyl derivative $\mathbf{2 c}$ was considerably lower than $\mathbf{3 a}$ and $\mathbf{3 b}$, because of the formation of a complicated mixture including $13 \%$ of $3 \mathbf{c}$ (see ESI, Figure S2). Unlike $\mathbf{2 a - c}$, homo-coupling reaction of benzyl-substituted analogue $\mathbf{2} \mathbf{d}$ did not proceed under the similar reaction conditions, while only desilylation was observed to give monomer $\mathbf{1 d}$. To get further insight into this reaction, we conducted reaction monitoring by NMR spectrometry (see ESI, Figure $\mathrm{S} 3$ ). The $\mathrm{Ag}_{2} \mathrm{O}$-mediated homocoupling reaction always competes with desilylation reaction of silyl enolate. ${ }^{6}$ While no significant difference was found in the rate of consumption of starting materials between $\mathbf{2 a}$ and $\mathbf{2 d}$, dimer was not formed in the reaction with $\mathbf{2 d}$. This is presumably because of the steric repulsion of benzyl substituents. However, cross-coupling reaction between $\mathbf{2 a}$ and $\mathbf{2 d}$ occurred in the presence of three equivalents of $\mathbf{2 a}$ to give tetraketone $\mathbf{3 e}$ in $18 \%$ yield. In a similar fashion, hetero-dimer $3 f$ was also obtained in $14 \%$ yield (Table 2 , entry 5,6 ). When cross-coupling reactions were performed in a 1:1 ratio of two silyl enolates, tetraketones $\mathbf{3 e}$ and $\mathbf{3 f}$ were formed in $14 \%$ and $11 \%$ yields, respectively. Use of large excess of $2 c$ did not improve the yield of $\mathbf{3 f}$. Notably, cross-coupling reaction with $\mathbf{2 d}$ is particularly advantageous owing to the absence of homodimer $\mathbf{3 d}$, as typically such cross-coupling reactions using two different monomers form a mixture of two homo-dimers and one hetero-dimer, rendering separation difficult. For example, in the synthesis of $\mathbf{3 e}$, the desired product was easily isolated from a mixture of $3 e$ and $40 \%$ of $3 a$ by silica gel column chromatography after the removal of desilylated monomers.

The crystal structure of dimer $\mathbf{3 b}$ showed the twisted structure for the main chain as previously observed for 3a (Figure 1). The central ethylene unit adopted a gauche configuration with the torsional angle of $64.4^{\circ}$. The (O)C-C-C(O) bond angles at the quaternary carbons were both $105.4^{\circ}$ which is slightly lower than those of $3 a\left(107.2^{\circ}\right)$ due to the 1,3 -diaxial interaction on the cyclohexane rings.

Table 2 Silver(I) oxide mediated coupling reactions ${ }^{a}$ of enol silyl ethers $\mathbf{2 a - d}$.

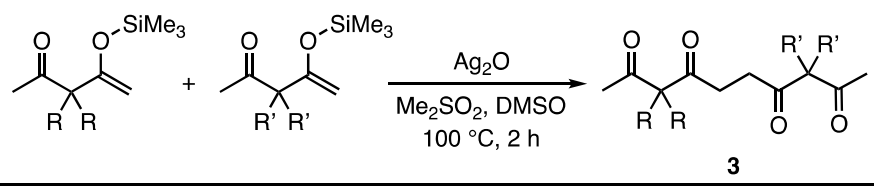<smiles>CC(=O)C(C)(C)C(=O)CCC(=O)C(C)(C)C(C)=O</smiles>

3a, $72 \%$<smiles>CC(=O)C1(C(=O)CCC(=O)C2(C(C)=O)CCCCC2)CCCCC1</smiles>

3b, $68 \%$<smiles>CC(=O)C1(C(=O)CCC(=O)C2(C(C)=O)CC2)CC1</smiles>

3c, $13 \%^{b}$<smiles>CC(=O)C(Cc1ccccc1)(Cc1ccccc1)C(=O)CCC(=O)C(Cc1ccccc1)(Cc1ccccc1)C(C)=O</smiles>

3d, $0 \%$<smiles>CC(=O)C(C)(C)C(=O)CCC(=O)C(Cc1ccccc1)(Cc1ccccc1)C(C)=O</smiles>

3e, $18 \%^{c}$

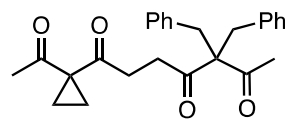

3f, $14 \%^{d}$
${ }^{a}$ General conditions for coupling reactions: enol silyl ether 2 (1.0 eq.), $\mathrm{Ag}_{2} \mathrm{O}$ (0.6 eq.), dimethyl sulfone (3.0 eq.), DMSO. ${ }^{b} \mathrm{NMR}$ Yield. ${ }^{c}$ Stoichiometry: $\mathbf{2 a} / \mathbf{2} \mathbf{d}=3: 1$; isolated yield is based on $\mathbf{2 d}$. ${ }^{d}$ Stoichiometry: $\mathbf{2 c} / \mathbf{2 d}=2: 1$; isolated yield is based on $\mathbf{2 d}$.

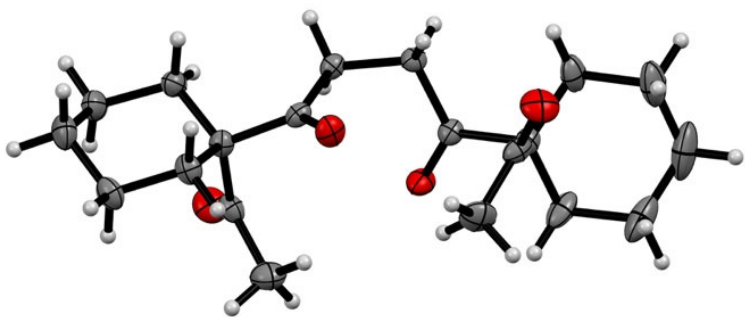

Figure 1 Crystal structure of $\mathbf{3 b}$. Thermal ellipsoids are set at the $50 \%$ probability (C: grey, O: red, H: off-white) 
Unique regioselectivity was found for silylation of tetraketones 3. Previously, we have demonstrated that homodimer $\mathbf{3 a}$ underwent terminal-selective silylation to give mono-silyl 4 a and bis-silyl 5 a in $42 \%$ and $26 \%$ yields, respectively, using two equivalents of chlorotrimethylsilane at $0{ }^{\circ} \mathrm{C}$ (Table 3 , entry 1$) .6$ Silylation reaction of cyclohexane analogue $\mathbf{3 b}$ under the similar reaction conditions to $\mathbf{3 a}$ was a bit sluggish. Mono- and bissilylated products $\mathbf{4} \mathbf{b}$ and $\mathbf{5 b}$ were obtained in $33 \%$ and $6 \%$ yields, respectively. When four equivalents of chlorotrimethylsilane was used with a longer reaction time, the yield of bis-silylated product $\mathbf{5 b}$ increased to be $42 \%$, while mono-silylated product $\mathbf{4 b}$ was still obtained in $16 \%$ yield along with $38 \%$ recovery of starting material $\mathbf{3 b}$ (Table 3 , entry 3 ). It is noteworthy that even with excess chlorotrimethylsilane, the internal carbonyl groups of $\mathbf{3 b}$ were completely resistant from silylation. However, longer reaction time or higher temperature caused over-silylation. These results imply that silylation is fast at the terminal acetyl groups connecting to a less bulky substituent.

Table 3 Terminal-selective silylation of tetraketones $3 .^{a}$

$3 \underset{\mathrm{Nal}, \mathrm{Et}_{3} \mathrm{~N}, \mathrm{MeCN}, 0{ }^{\circ} \mathrm{C}}{\longrightarrow}$

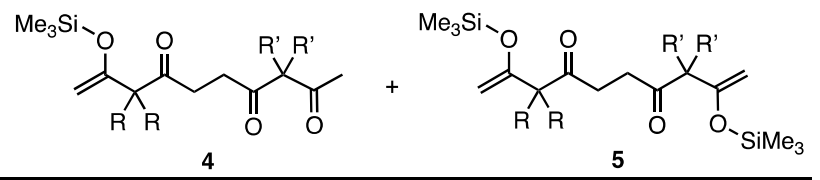

Entry Substrate (3)

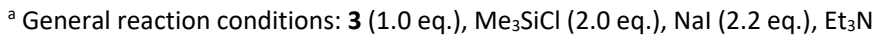
(2.2 eq.) in degassed $\mathrm{MeCN}$ at $0{ }^{\circ} \mathrm{C} .{ }^{\mathrm{b}} \mathrm{Me}_{3} \mathrm{SiCl}$ (4.0 eq.), $\mathrm{Nal}$ (4.4 eq.), $\mathrm{Et}_{3} \mathrm{~N}$ (4.4 eq.) were used. ${ }^{\mathrm{c}}$ Reaction was performed at $-10^{\circ} \mathrm{C}$.

More remarkable regioselectivity was observed for heterodimers $\mathbf{3 e}$ and $\mathbf{3} \mathbf{f}$. The first silylation of tetraketone $\mathbf{3 e}$ selectively occurred at the terminal acetyl group attached to the dimethylmethylene group. Thus, mono-silylated product $4 \mathbf{c}$ was obtained in $56 \%$ yield along with bis-silylated product $5 \mathrm{c}(17 \%)$.
In case of 3f, silylation at the cyclopropane terminal was much faster than dibenzyl terminal and the reaction was almost completed within $\mathbf{3 0}$ minutes to give mono-silylated product $\mathbf{4 d}$ in $86 \%$ yield. To our delight, bis-silylated $\mathbf{5 d}$ and other silylated byproducts were not obtained under this reaction condition. In the both cases for $\mathbf{3 e}$ and $\mathbf{3}$, the silylation site was confirmed by NOESY spectra (See ESI, Figure S32-S33). Strong correlations with exomethylene protons were observed for dimethylmethylene and cyclopropane protons for $\mathbf{3 e}$ and $\mathbf{3 f}$, respectively.

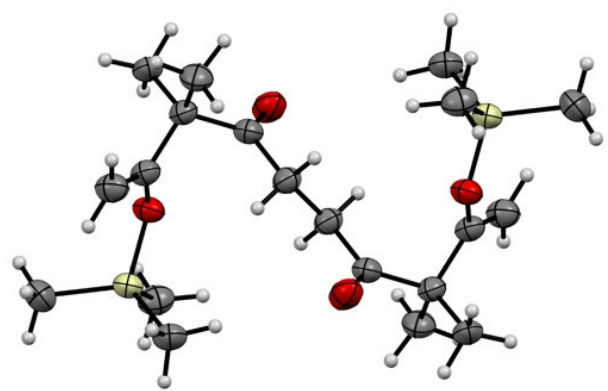

Figure 2 Crystal structure of compound 5a. Thermal ellipsoids are set at the $50 \%$ probability (C: grey, O: red, H: off-white, Si: yellow)

Single crystals of bis-silylated product $\mathbf{5 a}$ were obtained by cooling a viscous oil of $\mathbf{5 a}$ to $-20^{\circ} \mathrm{C}$. The crystal structure of $\mathbf{5 a}$ unambiguously confirmed that silylation occurred at the terminal carbonyl groups, leaving internal ones unreacted (Fig. 2). Interestingly, the solid-state conformation of the central ethylene unit was antiperiplanar in sharp contrast to $\mathbf{3 a}$, which adopted a gauche conformation. The regioselective silylation is useful to fabricate further longer polyketone chains with different substituents in a tailor-made sequence.
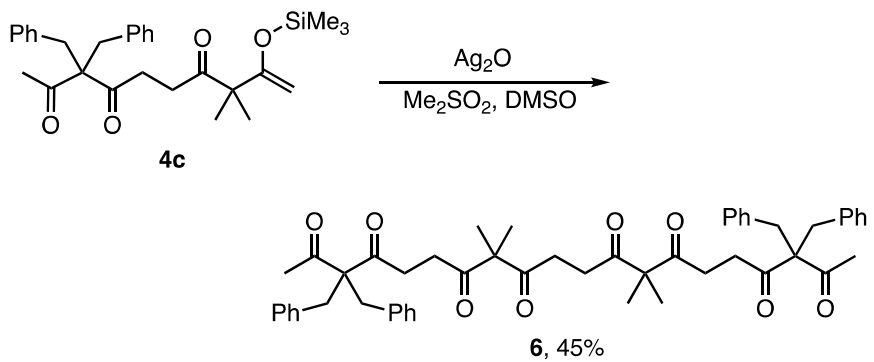

Scheme 1 Synthesis of octaketone 6 .

When silver(I) oxide-mediated homo-coupling reaction was performed using enol silyl ether 4c, octaketone $\mathbf{6}$ was isolated in $45 \%$ yield (Scheme 1). In this coupling reaction, the final product mixture was mainly composed of 6 and 3e (35\%) that was formed by desilylation. Therefore, pure and discrete 6 was readily obtained after chromatographic separation. 
Octaketones with another sequences of alkyl substituents were synthesized by cross-coupling reactions between bissilylated dimers and excess of mono-silylated monomers (Scheme 2). Octaketone $\mathbf{7}$ bearing a monomer sequence of $\mathbf{1 b}$ $\mathbf{1 a}-\mathbf{1 a}-\mathbf{1 b}$ was obtained in $\mathbf{3 0} \%$ yield from $\mathbf{5 a}$ and $\mathbf{2} \mathbf{b}$. When lesser amount of monomer $\mathbf{2} \mathbf{b}$ was used, polymeric products were generated from homo-coupling of $\mathbf{5 a}$. Octaketone $\mathbf{8}$, a structural isomer of $\mathbf{7}$ with a sequence of $\mathbf{1 a - 1} \mathbf{b}-\mathbf{1 b} \mathbf{- 1} \mathbf{a}$, was also synthesized with a similar protocol using $\mathbf{5 b}$ and $\mathbf{2 a}$ in $\mathbf{2 2 \%}$ yield.<smiles>[CH2]OC(=C)C(C)(C)C(=O)CCC(=O)C(C)(C)C(=O)OC</smiles>

$5 a$<smiles>C=C(O[Hg])C1(C(C)=O)CCCCC1</smiles>

$2 b$ (excess)<smiles>[Z6][Y6](=O)C(C)(C)C(=O)CCC(=O)C(C)(C)C(=O)CCC(=O)C1(C(C)=O)CCCCC1</smiles><smiles>C=C(OC)C1(C(=O)CCC(=O)C2(C(=C)O[Si])CCCCC2)CCCCC1</smiles>

$5 b$<smiles>C=C(O[Hg])C(C)(C)C(C)=O</smiles>

2a (excess)<smiles>CC(=O)C(C)(C)C(=O)CCC(=O)C1(C(=O)CCC(=O)C2(C(=O)CCC(=O)C(C)(C)C(C)=O)CCCCC2)CCCCC1</smiles>

Scheme 2 Synthesis of octaketones $\mathbf{7}$ and $\mathbf{8}$ by cross-coupling reactions.

Despite the same chemical formula, melting point of 7 (84 $\left.{ }^{\circ} \mathrm{C}\right)$ was significantly lower than that of $8\left(165^{\circ} \mathrm{C}\right)$. In order to fully understand such dissimilarity in their melting points, we conducted single crystal $\mathrm{X}$-ray analysis. Contrary to our expectation, both $\mathbf{7}$ and $\mathbf{8}$ adopt similar figure-S conformations (Fig. 3) as previously observed for octaketone with all dimethylmethylene groups. ${ }^{6}$ Namely, three ethylene-bridges in octaketones adopted gauche-antiperiplanar-gauche (from end-to-end) conformations, despite the difference in the substituent sequences. However, their packing structures were considerably different. While two crystal structures contained no solvent molecules, compound $\mathbf{7}$ had rather loose packing with a small solvent accessible void $(2.2 \%$ of the unit cell volume; probe radius: $1.2 \AA$ ). Isomer 8 showed tight packing without any solvent accessible void. The large difference in the melting points between $\mathbf{7}$ and $\mathbf{8}$ is attributed to the packing structure in the solid state. (a)

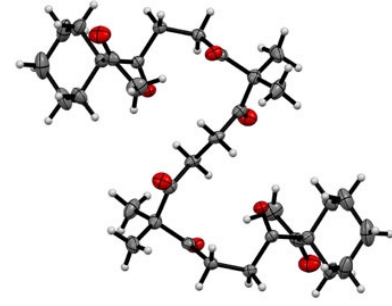

(b)

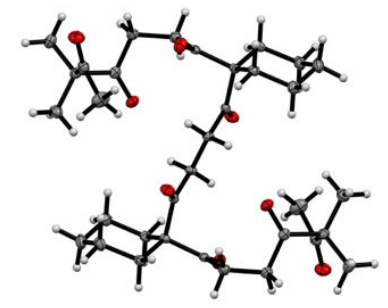

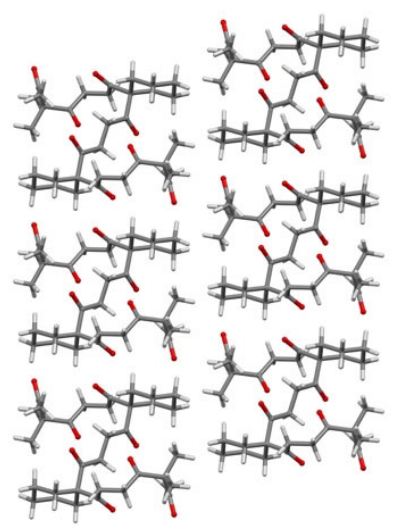

Figure 3 Crystal structures of octaketones (a) 7 and (b) 8. (left: ORTEP drawings at the $50 \%$ probability level; right: packing structures viewing along the $a$-axis) Solvent accessible voids are drawn in yellow.

\section{Conclusions}

In conclusion, we have demonstrated modular syntheses of aliphatic oligoketone chains based on the site-selective formation of enol silyl ethers. These approaches provide an efficient methodology to construct structurally defined, discrete polyketones with various sequences of substituents. Exclusive formation of mono-enol silyl ether from 3,3disubstituted acetylacetone derivatives promised scalability of the polyketone synthesis. The terminal-selective silylation with unique substituent dependence enabled the synthesis of octaketone chains with different substituent sequences. Single crystal X-ray analysis of oligoketones revealed that the chain conformations were governed by the carbonyl sequence rather than alkyl substituents. Nevertheless, slight differences in the packing structures of structural isomers $\mathbf{7}$ and $\mathbf{8}$ resulted in the large difference in their melting points. Given a variety of postsynthetic reactions and applications, ${ }^{7-9}$ aliphatic oligoketones prepared in this work are expected to be good scaffold for a lot of functional materials. 


\section{Experimental}

\section{Crystallographic data of compound $3 b$}

Single crystals of $\mathbf{3} \mathbf{b}$ were grown by vapor diffusion of the solution in diethyl ether and $n$-hexane. Colourless plate-like crystal of approximate size $0.60 \times 0.45 \times 0.32 \mathrm{~mm}^{3}$, was used for data collection. $\mathrm{C}_{20} \mathrm{H}_{30} \mathrm{O}_{4}, M_{\mathrm{W}}=334.44$, Monoclinic, space group $P 2_{1} / n, a=9.8166$ (4) $\AA, b=12.8538(5) \AA, c=14.9915(7) \AA, b=98.444(4)^{\circ}, V=1871.13(14)$ $\AA^{3}, Z=4, T=123(2) \mathrm{K}, \mu=0.081 \mathrm{~mm}^{-1}, D_{\text {calc }}=1.187 \mathrm{~g} / \mathrm{cm}^{3}, 2.332^{\circ} \leq \vartheta$ $\leq 26.995^{\circ}, 3605$ unique reflections out of 4072 with $I>2 \sigma(l)$, GOF $=$ 1.058, $R_{1}=0.0562, w R_{2}=0.1528$. CCDC deposit number: 1987571 .

\section{Crystallographic data of compound 5 a}

Single crystals of $\mathbf{5 a}$ were grown at low temperature from viscous oil of the pure material. Colourless needle-like crystal of approximate size $0.32 \times 0.26 \times 0.09 \mathrm{~mm}^{3}$, was used for data collection. $\mathrm{C}_{20} \mathrm{H}_{38} \mathrm{O}_{4} \mathrm{Si}_{2}$, $M_{\mathrm{W}}=398.69$, Monoclinic, space group $P 2_{1} / c, a=7.1033(14) \AA, b=$ 15.700(3) $\AA, c=10.748(2) \AA, b=90.224(6)^{\circ}, V=1198.7(4) \AA^{3}, Z=4, T$ $=123(2) \mathrm{K}, \mu=0.167 \mathrm{~mm}^{-1}, D_{\text {calc }}=1.105 \mathrm{~g} / \mathrm{cm}^{3}, 1.895^{\circ} \leq \vartheta \leq 27.483^{\circ}$, 2002 unique reflections out of 2726 with $I>2 \sigma(I), \mathrm{GOF}=1.075, R_{1}=$ $0.0694, w R_{2}=0.1738$. CCDC deposit number: 1987572 .

\section{Crystallographic data of compound 7}

Single crystals of $\mathbf{7}$ were grown by slow evaporation of the solution in chloroform at room temperature. Colourless needle-like crystal of approximate size $0.58 \times 0.12 \times 0.03 \mathrm{~mm}^{3}$, was used for data collection. $\mathrm{C}_{34} \mathrm{H}_{50} \mathrm{O}_{8}, M_{\mathrm{W}}=586.74$, Triclinic, space group $P$-1, $a=7.0479$ (2) $\AA, b$ $=10.1584(4) \AA, c=11.6894(4) \AA, \alpha=91.402(3)^{\circ}, b=99.676(3)^{\circ}, v=$ $96.997(3)^{\circ}, V=817.99(5) \AA^{3}, Z=1, T=123(2) \mathrm{K}, \mu=0.083 \mathrm{~mm}^{-1}, D_{\text {calc }}$ $=1.191 \mathrm{~g} / \mathrm{cm}^{3}, 2.625^{\circ} \leq \vartheta \leq 26.989^{\circ}, 2919$ unique reflections out of 3522 with $I>2 \sigma(I), \mathrm{GOF}=1.029, R_{1}=0.0451, w R_{2}=0.1254 . \mathrm{CCDC}$ deposit number: 1987573.

\section{Crystallographic data of compound 8}

Single crystals of $\mathbf{8}$ were grown by vapor diffusion of the solution in chloroform and methanol. Colourless needle-like crystal of approximate size $0.70 \times 0.38 \times 0.04 \mathrm{~mm}^{3}$, was used for data collection. $\mathrm{C}_{34} \mathrm{H}_{50} \mathrm{O}_{8}, M=586.74$, Triclinic, space group $P-1, a=7.3875(2) \AA, b=$ 9.2832(3) $\AA, c=11.5913(3) \AA, \alpha=103.164(3)^{\circ}, b=95.845(2)^{\circ}, y=$ $95.145(2)^{\circ}, V=764.77(4) \AA^{3}, Z=1, T=123(2) \mathrm{K}, \mu=0.089 \mathrm{~mm}^{-1}, D_{\text {calc }}$ $=1.274 \mathrm{~g} / \mathrm{cm}^{3}, 2.269^{\circ} \leq \vartheta \leq 26.993^{\circ}, 2958$ unique reflections out of 3318 with $I>2 \sigma(I), \mathrm{GOF}=1.046, R_{1}=0.0350, w R_{2}=0.0932 . \mathrm{CCDC}$ deposit number: 1987574.

\section{Conflicts of interest}

"There are no conflicts to declare".

\section{Acknowledgements}

This work was supported by Grant-in-Aid for Young Scientists (A) (No. 17H04872) and by the Asahi Glass Foundation, of which Y.I. is the principal investigator. Institute for Chemical Reaction Design and Discovery (ICReDD) was established by World Premier International Research Initiative (WPI), MEXT, Japan.
\# Footnotes relating to the main text should appear here. These might include comments relevant to but not central to the matter under discussion, limited experimental and spectral data, and crystallographic data.

1 (a) C. Hertweck, Angew. Chem. Int. Ed., 2009, 48, 4688; (b) B. A. Pfeifer and C. Khosla, Microbiol. Mol. Biol. Rev. 2001, 65, 106.

2 A. Vavasori, L. Ronchin, "Polyketones: synthesis and applications" in Encyclopaedia of Polymer Science and Technology, John Wiley \& Sons, Inc. Hoboken, 2017, 1-41.

3 C. Bianchini and A. Meli, Coord. Chem. Rev., 2002, 225, 35.

4 (a) P. J. Wittek and T. M. Harris, J. Am. Chem. Soc. 1973, 95 6865; (b) A. J. Birch, P. Fitton, D. C. C. Smith, D. E. Steere and A. R. Stelfox, J. Chem. Soc. 1963, 2209; (c) L. Kersten, K. Harms and G. Hilt, J. Org. Chem, 2014, 79, 11661. (d) M. Yamaguchi, K. Hasebe, H. Higashi, M. Uchida, A. Irie and T. Minami, J. Org. Chem, 1990, 55, 1611; (e) V. C. Fäseke, F. C. Raps and C. Sparr, Angew. Chem. Int. Ed., in press (DOI: 10.1002/anie.201911255).

5 (a) Y. Zhang, A. A. Broekhuis, M. C. A. Stuart and F. Picchioni, J. Appl. Polym. Sci., 2008, 107, 262; Z. Jiang, S. Sanganeria and A. Sen, J. Polym. Sci., Part A: Polym. Chem. 1994, 32, 841; (b) P. C. Zehetmaier, S. I. Vagin and B. Rieger, MRS Bull., 2013, 38, 239.

6 M. Uesaka, Y. Saito, S. Yoshioka, Y. Domoto, M. Fujita and Y. Inokuma, Commun. Chem, 2018, 1, 23.

7 (a) Y. Saito, M. Higuchi, S. Yoshioka, H. Senboku and Y. Inokuma, Chem. Commun. 2018, 54, 6788; (b) Y. Manabe, M. Uesaka, T. Yoneda and Y. Inokuma, J. Org. Chem. 2019, 84, 9957; (c) Y. Inaba, T. Yoneda, Y. Kitagawa, K. Miyata, Y. Hasegawa and Y. Inokuma, Chem. Commun. 2020, 56, 348.

8 T. Eriksson, A. Mace, Y. Manabe, M. Yoshizawa-Fujita, Y. Inokuma, D. Brandell, J. Mindemark, J. Electrochem. Soc. 2020, $167,070537$.

9 (a) Y. Ashida, Y. Manabe, S. Yoshioka, T. Yoneda and Y. Inokuma, Dalton Trans. 2019, 48, 818; (b) T. Yoneda, C. Kasai, Y. Manabe, M. Tsurui, Y. Kitagawa, Y. Hasegawa, P. Sarkar, Y. Inokuma, Chem. Asian J., 2020, 15, 601.

10 K. Beck, S. Hunig, Chem. Ber., 1987, 20, 477.

11 D. S. Siegel, G. Piizzi, G. Piersanti, M. Movassaghi, J. Org. Chem, 2009, 74, 9292.

12 U. Sankar, C. Raju, R. Uma, Curr. Chem. Lett. 2012, 1, 123.

\section{Notes and references}

